severe adverse events, namely a case of hemiparesis in a patient with systemic sclerosis/SLE overlap syndrome (ongoing at the time of reporting), and a case of giant cell arteritis in a patient with osteoarthritis (recovered/resolved without sequelae). Conclusion: The safety profiles for COVID-19 vaccines in RMD patients was reassuring. Most adverse events were the same as in the general population, they were non-serious and involved short term local and systemic symptoms. The overwhelming majority of patients tolerated their vaccination well with rare reports of inflammatory RMD flare (5\%; $1.2 \%$ severe) and very rare reports of severe adverse events $(0.1 \%)$. These initial findings should provide reassurance to rheumatologists and vaccine recipients, and promote confidence in COVID-19 vaccine safety in RMD patients, namely those with inflammatory RMDs and/or taking treatments that influence their immune system.

Acknowledgements: EULAR COVID-19 Task Force; European Reference Network on rare and Complex Connective Tissue and Musculoskeletal Diseases; European Reference Network on Rare Immunodeficiency, Autoinflammatory and Autoimmune Diseases Network; all rheumatologists contributing to the EULAR COVAX Registry.

Disclosure of Interests: Pedro M Machado Consultant of: Abbvie, BMS, Celgene, Eli Lilly, Janssen, MSD, Novartis, Orphazyme, Pfizer, Roche and UCB, all unrelated to this manuscript., Grant/research support from: Orphazyme, unrelated to this manuscript., Speakers bureau: Abbvie, BMS, Celgene, Eli Lilly, Janssen, MSD, Novartis, Orphazyme, Pfizer, Roche and UCB, all unrelated to this manuscript., Saskia Lawson-Tovey: None declared, Kimme Hyrich Grant/research support from: BMS, UCB, and Pfizer, all unrelated to this manuscript., Speakers bureau: Abbvie, Loreto Carmona Consultant of: her institute works by contract for laboratories among other institutions, such as Abbvie Spain, Eisai, Gebro Pharma, Merck Sharp \& Dohme España, S.A., Novartis Farmaceutica, Pfizer, Roche Farma, Sanofi Aventis, Astellas Pharma, Actelion Pharmaceuticals España, Grünenthal GmbH, and UCB Pharma, all unrelated to this manuscript., Laure Gossec Grant/research support from: AbbVie, Amgen, BMS, Biogen, Celgene, Gilead, Janssen, Lilly, Novartis, Pfizer, Samsung Bioepis, Sanofi-Aventis, UCB, all unrelated to this manuscript., Speakers bureau: Amgen, Lilly, Janssen, Pfizer, Sandoz, Sanofi, Galapagos, all unrelated to this manuscript., Elsa Mateus Grant/research support from: LPCDR received support for specific activities: grants from Abbvie, Novartis, Janssen-Cilag, Lilly Portugal, Sanofi, Grünenthal S.A., MSD, Celgene, Medac, Pharmakern, GAfPA; grants and non-financial support from Pfizer; non-financial support from Grünenthal $\mathrm{GmbH}$, outside the submitted work., Anja Strangfeld Speakers bureau: AbbVie, MSD, Roche, BMS, and Pfizer, all unrelated with this manuscript., BERND RAFFEINER: None declared, Tiphaine Goulenok: None declared, Olilvier Brocq: None declared, Martina Cornalba: None declared, José A Gómez-Puerta Speakers bureau: AbbVie, BMS, GSK, Janssen, Lilly, MSD, Roche and Sanofi., Eric Veillard: None declared, Ludovic Trefond: None declared, Jacques-Eric Gottenberg: None declared, Julien Henry: None declared, Patrick Durez: None declared, Gerd Rüdiger Burmester: None declared, Marta Mosca: None declared, Eric Hachulla: None declared, Hans Bijlsma: None declared, lain Mclnnes: None declared, Xavier Mariette Consultant of: BMS, Galapagos, Gilead, Janssen, Novartis, Pfizer, Sanofi-Aventis, UCB, and grant from Ose, all unrelated to this manuscript.

DOI: 10.1136/annrheumdis-2021-eular.5097

\section{LB0003 \\ IMMUNOGENICITY AND SAFETY OF THE BNT162B2 MRNA COVID-19 VACCINE IN ADULT PATIENTS WITH AUTOIMMUNE INFLAMMATORY RHEUMATIC DISEASES AND GENERAL POPULATION: A MULTICENTER STUDY}

$\underline{\text { V. Furer }}^{1}$, T. Eviatar ${ }^{1}$, D. Zisman², H. Peleg ${ }^{3}$, D. Paran ${ }^{1}$, D. Levartovsky ${ }^{1}$, M. Zisapel ${ }^{1}$, O. Elalouf ${ }^{1}$, I. Kaufman ${ }^{1}$, R. Meidan ${ }^{1}$, A. Broyde ${ }^{1}$, A. Polachek ${ }^{1}$, J. Wollman ${ }^{1}$, I. Litinsky ${ }^{1}$, K. Meridor ${ }^{1}$, H. Nochomovitz ${ }^{1}$, A. Silberman ${ }^{1}$, D. Rosenberg ${ }^{1}$, J. Feld ${ }^{2}$, A. Haddad ${ }^{2}$, T. Gazitt ${ }^{2}$, M. Elias ${ }^{2}$, N. Higazi ${ }^{2}$, F. Kharouf ${ }^{3}$, G. Shefer ${ }^{4}$, O. Sharon ${ }^{4}$, S. Pel ${ }^{1}$, S. Nevo ${ }^{1}$, O. Elkayam ${ }^{1} .{ }^{1} \mathrm{Tel}$ Aviv Medical Center, Rheumatology, Tel Aviv, Israel; ${ }^{2}$ Carmel Medical Center, Rheumatology, Haifa, Israel; ${ }^{3} \mathrm{Hadassah}$ Medical Center, Rheumatology, Jerusalem, Israel; ${ }^{4}$ Tel Aviv Medical Center, Endocrinology, Tel Aviv, Israel

Background: Vaccination represents a cornerstone in mastering the COVID-19 pandemic. Data on immunogenicity, efficacy, and safety of the novel BNT162b2 mRNA vaccine in patients with autoimmune inflammatory rheumatic diseases (AIIRD) are limited.
Objectives: To investigate the immunogenicity, efficacy, and safety of the BNT162b2 mRNA vaccine in patients with AlIRD compared to the general population.

Methods: A prospective multicenter study investigated immunogenicity, efficacy, and safety of the two-dose regimen BNT162b2 mRNA vaccine in adult patients with AIIRD including rheumatoid arthritis (RA), psoriatic arthritis (PsA), axial spondyloarthropathy ( $\operatorname{axSpA})$, systemic lupus erythematosus (SLE), connective tissues diseases (CTD), systemic vasculitides, and idiopathic inflammatory myositis (IIM), compared to control subjects without rheumatic diseases or immunosuppressive therapies. Serum IgG antibody levels against SARS-CoV-2 spike S1/S2 proteins were measured 2 - 6 weeks after the second vaccine dose. Seropositivity was defined as $\lg \mathrm{G} \geq 15$ binding antibody units $(B A U) / \mathrm{ml}$. Post-vaccination efficacy defined as post-vaccination COVID-19 infection and safety were assessed. Preand post- vaccination disease activity indices were assessed as appropriate for each disease.

Results: A total of 686 AlIRD patients and 121 controls participated into the study. AIIRD patients were significantly older than controls, mean age \pm SD $56.76 \pm 14.88$ vs $50.76 \pm 14.68$, respectively, $p<0.0001$. A total of $95.2 \% \quad(n=653)$ AlIRD patients were treated with immunomodulatory medications.

The seropositivity rate was $86 \%(n=590)$ in patients with AlIRD compared to $100 \%$ in controls $(p<0.0001$ ) The level of the S1/S2 antibodies was significantly reduced in AlIRD patients compared to controls (mean \pm SD $132.9 \pm 91.7$ vs 218.6 $\pm 82.06, P<0.0001)$. In patients with $P s A, A x S p A, S L E$, and LVV, the seropositive rate was above $90 \%$. In RA, the seropositive rate was $82.1 \%$ and the lowest seropositive rate $(<40 \%)$ was observed in patients with AAV and IIM. Anti-CD20 significantly impaired the vaccine's immunogenicity, with the lowest seropositivity rate of $39 \%$. The use of GC, mycophenolate mofetil (MMF), and abatacept was associated with a significantly lower rate of seropositivity (Figure 1). MTX significantly reduced the seropositivity in patients treated with MTX monotherapy and in combinations with other treatments $(92 \%$ and $84 \%$, respectively), although at a lesser magnitude than anti-CD20, MMF, and abatacept. More than $97 \%$ of patients treated with anti-cytokine therapies including TNFi, interleukin-17 and interleukin- 6 inhibitors had an appropriate immunogenic response when used as monotherapy. The combination of TNFi with MTX significantly reduced the rate of seropositivity to $93 \%, p=0.04$. Age over 65 years, a diagnosis of RA, IIM, ANCA-associated vascilitis, and treatment with GC, MMF, anti-CD20, and abatacept were associated with a reduced likelihood of seropositivity.

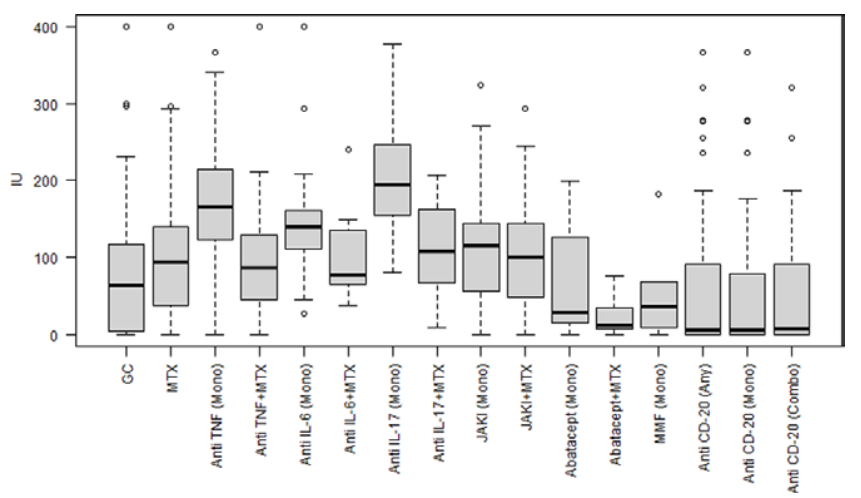

Figure 1. Seropositivity rate by immunosuppressive treatment.

There were no post-vaccination symptomatic cases of COVID-19 among AIIRD patients and one mild case in the control group. Major adverse events in AIIRD patients included death $(n=2)$ several weeks after the second vaccine dose, non-disseminated herpes zoster $(n=6)$, uveitis $(n=2)$, and pericarditis $(n=1)$. Post-vaccination disease activity remained stable in the majority of patients.

Conclusion: Vaccination with the BNTb262 vaccine resulted in an adequate immunogenic response with an acceptable safety profile in the majority of patients with AIIRD. Treatment with GC, rituximab, MMF, and abatacept may impair BNT162b2-induced immunogenicity. Postponing administration 
of rituximab, when clinically feasible, seems to be reasonable to improve vaccine-induced immunogenicity. Holding treatment with abatacept and MMF may be considered on an individual basis

Disclosure of Interests: None declared

DOI: 10.1136/annrheumdis-2021-eular.5096

\section{LB0004 $\quad$ EFFICACY AND SAFETY OF SECUKINUMAB IN ENTHESITIS-RELATED ARTHRITIS AND JUVENILE PSORIATIC ARTHRITIS: PRIMARY RESULTS FROM A RANDOMISED, DOUBLE-BLIND, PLACEBO- CONTROLLED, TREATMENT WITHDRAWAL, PHASE 3 STUDY (JUNIPERA)}

N. Ruperto ${ }^{1}$, I. Foeldvari ${ }^{2}$, E. Alexeeva ${ }^{3}$, N. Aktay Ayaz ${ }^{4}$, I. Calvo ${ }^{5}$, O. Kasapcopur ${ }^{6}$, V. Chasnyk ${ }^{7}$, M. Hufnagel ${ }^{8}$, Z. Żuber ${ }^{9}$, G. Schulert ${ }^{10}$ S. Ozen ${ }^{11}$, A. Popov ${ }^{12}$, A. Ramanan ${ }^{13}$, C. Scott ${ }^{14}$, B. Sözeri ${ }^{15}$, E. Zholobova ${ }^{16}$, X. Zhu ${ }^{17}$, S. Whelan ${ }^{18}$, L. Pricop ${ }^{19}$, A. Ravelli ${ }^{20}$, A. Martini ${ }^{21}$, D. J. Lovell ${ }^{22}$, H. Brunner ${ }^{23}$ on behalf of PRCSG and PRINTO investigative sites. ${ }^{1}$ IRCCS Istituto G. Gaslini, Università di Genova Pediatria, Pediatrics, Genova, Italy; ${ }^{2}$ Hamburger Zentrum fuer Kinder und Jugendrheumatologie, Pediatrics, Hamburg, Germany; ${ }^{3}$ National Scientific and Practical Center of Children's Health, Pediatrics, Moscow, Russian Federation; ${ }^{4}$ Istanbul University, Pediatric Rheumatology, Istanbul, Turkey; ${ }^{5}$ Hospital Universitario i Politecnic La Fe Valencia, Pediatrics, Valencia, Spain; ${ }^{6}$ İstanbul UniversityCerrahpaşa, Cerrahpaşa Faculty of Medicine, Pediatrics, Istanbul, Turkey; ${ }^{7}$ St. Petersburg State Pediatric Medical Academy, Pediatrics, St. Petersburg, Russian Federation; ${ }^{8}$ University of Freiburg, Pediatrics and Adolescent Medicine, Freiburg, Germany; ${ }^{9}$ Wojewodzki Specjalistyczny Szpital Dzieciecy im Sw Ludwika, Pediatrics, Krakow, Poland; ${ }^{10}$ University of Cincinnati, Pediatrics, Ohio, United States of America;

${ }^{11}$ Hacettepe University Medical Faculty, Pediatrics, Ankara, Turkey;

${ }^{12}$ Ural State Medical University, Pediatrics, Yekaterinburg, Russian Federation; ${ }^{13}$ University Hospitals Bristol NHS Foundation Trust and Bristol Medical School, University of Bristol, Bristol, UK, Pediatrics, Bristol, United Kingdom; ${ }^{14}$ University of Cape Town, Paediatric Rheumatology, Cape Town, South Africa; ${ }^{15} \mathrm{Health}$ Sciences University, Pediatric Rheumatology, Istanbul, Turkey; ${ }^{16}$ First Moscow State Medical University, Pediatrics, Moscow, Russian Federation; ${ }^{17}$ Novartis Pharmaceutical Corporation, Biostatistics, East Hanover, United States of America; ${ }^{18}$ Novartis Ireland Limited, Clinical Development, Dublin, Ireland; ${ }^{19}$ Novartis Pharmaceutical Corporation, Clinical Development, East Hanover, United States of America; ${ }^{20}$ Istituto Giannina Gaslini, and Università degli Studi di Genova, Pediatrics, Genova, Italy; ${ }^{21}$ IRCCS Istituto G. Gaslini, Università di Genova Pediatria II, Pediatrics, Genova, Italy; ${ }^{22}$ Cincinnati Children's Hospital Medical Center, University of Cincinnati, Rheumatology, Cincinnati, United States of America ${ }^{23}$ University of Cincinnati, Pediatrics, Cincinnati, United States of America

Background: Enthesitis-related arthritis (ERA) and juvenile psoriatic arthritis (JPSA) are two ILAR categories of juvenile idiopathic arthritis (JIA) and represent paediatric correlates of axial spondyloarthritis (axSpA) and adult psoriatic arthritis (PSA), respectively. ${ }^{1,2}$ Secukinumab (SEC) has demonstrated efficacy and safety in adult patients (pts) with PsA, ankylosing spondylitis and non-radiographic axSpA..$^{3-5}$

Objectives: Evaluate efficacy and safety of SEC using a flare prevention design in pts with active ERA and JPsA.

Methods: This 2-yr study consisted of an open-label (OL) s.c. SEC $(75 / 150 \mathrm{mg}$ in pts $<50 / \geq 50 \mathrm{~kg})$ at baseline $(\mathrm{BL})$, and at Weeks (Wk) 1, 2, $3,4,8$ and 12 in treatment-period (TP) 1. Responder pts who achieved at least JIA ACR 30 response at WK 12 were randomised into the double-blinded TP2 to continue SEC or placebo (PBO) q4w until a disease flare, or up to Wk 100. Pts (aged 2 to $<18 \mathrm{yrs}$ ) classified as ERA or JPSA according to ILAR criteria of $\geq 6$ months duration with active disease were included. Primary endpoint was time to flare in TP2 and key secondary endpoints were JIA ACR 30/50/70/90/100, inactive disease, JADAS, enthesitis count and safety. Analysis of time to flare in TP2 included proportion of disease flare, Kaplan-Meier (KM) estimate of median time to flare in days, hazard ratio $(95 \% \mathrm{Cl})$ from Cox model, and $P$-value for the Stratified log-rank test. KM estimates of the probability to disease flare by treatment groups in TP2 were plotted against days. Observed data were used in all analyses. Post-hoc analyses using non-responder imputation (NRI) were performed for JIA ACR 30/50/70/90/100 responses.

Results: $86 / 97$ (89\%) pts were enrolled in the OL period TP1 (mean age $13.1 \mathrm{yrs}$; female, 33.7\%; ERA, $n=52 ;$ JPsA, $n=34$ ). At $B L$, mean JADAS-27 score was 15.1 and enthesitis count was 2.6. At the end of TP1, $90.4 \%$ (75/83) of pts achieved JIA ACR 30 and $69.9 \%$ (58/83) achieved JIA ACR 70. There were 21 and 10 flares in TP2, respectively in PBO and SEC treated pts with a significantly longer time to flare and $72 \%$ risk of flare reduction in SEC treatment vs PBO (HR: $0.28 ; 95 \% \mathrm{Cl}: 0.13-0.63 ; P<0.001)$ (Figure 1). JIA ACR responses, disease activity and enthesitis count are reported in Table 1. NRI analyses showed that $87.2 \%, 83.7 \%, 67.4 \%, 38.4 \%$ and $24.4 \%$ of pts achieved JIA ACR $30 / 50 / 70 / 90 / 100$, respectively. Rates of adverse events (AEs; $91.7 \%$ vs $92.1 \%$ ) and serious AEs (14.6\% vs $10.5 \%$ ) in SEC and PBO groups were comparable in the entire TP. No new safety signals were observed.

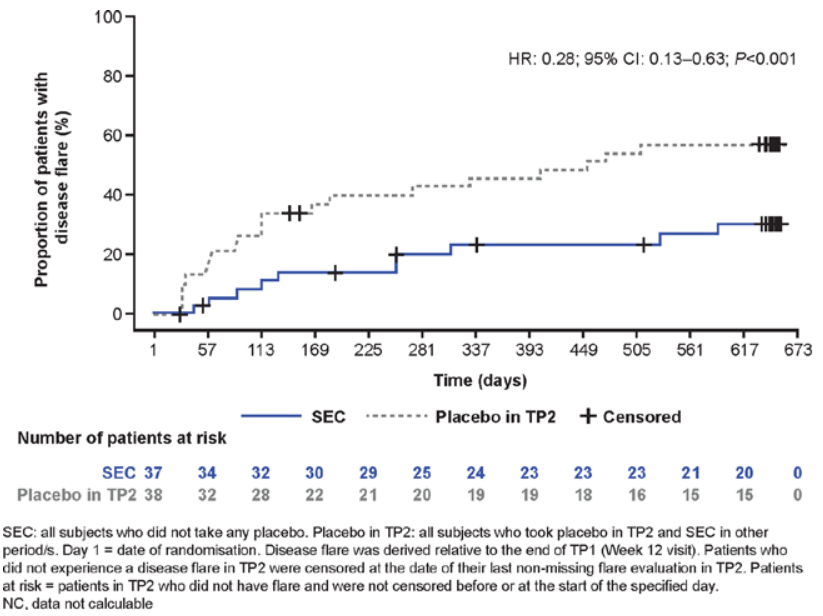

Figure 1. Time to flare in Treatment Period 2 (Primary Endpoint)

Table 1. Efficacy of secukinumab in Treatment Periods 1 and 2 (Key secondary endpoints)

\begin{tabular}{|c|c|c|c|c|}
\hline \multirow[b]{2}{*}{ Efficacy Outcomes, \% } & \multirow{2}{*}{$\frac{\text { TP1 }}{\operatorname{SEC}(\mathrm{N}=83)}$} & \multicolumn{3}{|l|}{$\mathrm{TP}^{*}$} \\
\hline & & SEC $(\mathrm{N}=37)$ & ) $\mathrm{PBO}(\mathrm{N}=37)$ & $P$-value \\
\hline JIA ACR 30 & 90.4 & 89.2 & 64.9 & 0.014 \\
\hline JIA ACR 50 & 86.7 & 78.4 & 62.2 & 0.152 \\
\hline JIA ACR 70 & 69.9 & 67.6 & 43.2 & 0.042 \\
\hline JIA ACR 90 & 39.8 & 51.4 & 40.5 & 0.431 \\
\hline JIA ACR 100 & 25.3 & 43.2 & 37.8 & 0.745 \\
\hline Inactive disease ${ }^{\#}$ & 36.1 & 47.2 & 37.8 & 0.500 \\
\hline JADAS-27, mean (SD) & $15.1(7.2)$ & $14.6(8.1)$ & $13.3(5.8)$ & NA \\
\hline Enthesitis count, mean change from BL (SD) & $-1.8(2.3)$ & $-2.1(2.0)$ & $-1.9(1.2)$ & NA \\
\hline
\end{tabular}

P-values: Cochran-Mantel-Haenszel test, adjusted for analysis factors: JIA category (ERA JPsA) and MTX use at BL

${ }^{¥}$ The $\mathrm{N}$ numbers are values at the end of TP2

${ }^{\wedge}$ Efficacy outcomes (\%) in TP1 calculated in patients with evaluable data at Wk 12 ( $\mathrm{N}=83$ )

\#Inactive disease: Definition adapted from JIA ACR criteria of Wallace et al., 2011. N=36 for SEC at the end of TP2

JADAS, Juvenile Arthritis Disease Activity Score; N, total number of patients in the treatment group; NA, data not available

Conclusion: In children and adolescents with ERA and JPsA, efficacy of SEC was demonstrated with a significantly longer time to flare vs PBO with sustained improvement of signs and symptoms up to Wk 104 and a favourable safety profile. 